\title{
De pandemias, movilidad al extranjero y resiliencia: perspectivas estudiantiles y docentes
}

\author{
Josefina Guerrero García, Ricardo Villegas Tovar y Vivian Cuevas Caballero
}

\begin{abstract}
Resumen
Vivir una experiencia internacional brinda la oportunidad de adquirir nuevos conocimientos y la posibilidad de desarrollar competencias personales y profesionales para ser individuos competitivos en un mundo globalizado y multicultural. Sin embargo, con la llegada de la covid-19, algunos países establecieron fuertes restricciones en sus flujos migratorios y cerraron fronteras. Por ello, gran parte de los programas de movilidad estudiantil y docente coordinados por universidades se vieron suspendidos o postergados. La actual situación con la pandemia exige cuidarnos, mantener distanciamiento social, incrementar las actividades en línea y reducir la movilidad física. Ante la incertidumbre que aún impera en el mundo, pareciera haber un escenario negativo para la movilidad de estudiantes y docentes. En ese sentido, este artículo presenta la perspectiva de un grupo de estudiantes y docentes, consultados a través de entrevistas y seminarios virtuales, sobre cómo vivir una experiencia internacional a partir de la actual pandemia. Entre los hallazgos, si bien no puede afirmarse que la percepción de todos los individuos sea positiva, el panorama se vislumbra alentador.
\end{abstract}

Palabras clave: movilidad universitaria, covid-19, internacionalización, educación superior.

\section{ON PANDEMICS, STUDIES ABROAD, AND RESILIENCE: STUDENTS AND TEACHERS' PERSPECTIVES}

\begin{abstract}
Living an international experience provides the opportunity to acquire new knowledge and the possibility of developing personal and professional skills to be competitive individuals in a globalized and multicultural world. However, with the arrival of covID-19, some countries established strong restrictions on their migratory flows, closing borders. Therefore, a large part of the student and teacher mobility programs coordinated by universities were suspended or postponed. The current situation with the pandemic requires taking care of ourselves, maintaining social distancing, increasing online activities and reducing physical mobility. Given the uncertainty that still prevails in the world, there seems to be a negative scenario for the mobility of students and teachers. In this sense, this article presents the perspective of a group of students and teachers, consulted through interviews and virtual seminars, on how to live an international experience in the current pandemic. Among the findings, although it cannot be said that the perception of all individuals is positive, the outlook looks encouraging.
\end{abstract}

Keywords: study abroad, covID-19, internationalization, higher education.

Recepción: 08/04/2021. Aprobación: 09/06/2021. Dol: http://doi.org/10.22201/cuaieed.16076079e.2021.22.5.12 
"De pandemias, movilidad al extranjero y resiliencia: perspectivas estudiantiles y docentes" Josefina Guerrero García, Ricardo Villegas Tovar y Vivian Cuevas Caballero Vol. 22, Núm. 5, septiembre-octubre 2021

Revista Digital Universitaria

Josefina Guerrero García

josefina.guerrero@correo.buap.mx orcid.org/0000-0002-3393-610X

scholar.google.com/citations?user=NZbIVmwAAAAJ\&hl=es

Es doctora por la Facultad de Ciencias Económicas y de Administración, con especialización en Sistemas de Información de la Université catholique de Louvain (Bélgica). Es miembro del Laboratorio de Informática en Interacción Humano-Computadora (BCHI) en Bélgica y del Consorcio UsixmL. De forma adicional, es integrante del cuerpo académico consolidado "Sistemas y Ambientes Educativos BUAP-CA-320"; del Sistema Nacional de Investigadores, nivel I y del Padrón de Investigadores BUAP; cuenta con perfil deseable PRODEP y es miembro de la Red HCI-Collab de la AuIP. Actualmente es Profesora Investigadora de la Benemérita Universidad Autónoma de Puebla (BUAP) en la Facultad de Ciencias de la Computación, para el Doctorado en Sistemas y Ambientes Educativos y el Doctorado en Ingeniería del Lenguaje y del Conocimiento.

\section{Ricardo Villegas Tovar}

ricardo.villegas@correo.buap.mx orcid.org/0000-0002-3222-6624

Es Doctor en Ciencias de Gobierno y posee un Máster en Derecho de la Propiedad Intelectual otorgado conjuntamente por la Universidad de Turín, Italia y la Academia de la Organización Mundial de la Propiedad Intelectual (cum laude). Se ha desenvuelto en el medio de la información científica por los últimos veinte años. Asimismo, ha colaborado con el Instituto Mexicano para la Administración del Conocimiento, al impartir desde 2004 seminarios sobre Derecho de Autor y Derecho a la Información. A partir de 2017 asumió la Coordinación de Producción Académica y Visibilidad Internacional en la Dirección de Desarrollo Internacional, y actualmente continúa con la misma encomienda en la Vicerrectoría de Investigación y Estudios de Posgrado, dentro de la Benemérita Universidad Autónoma de Puebla (BUAP).

\section{Vivian Cuevas Caballero}

$$
\begin{array}{r}
\text { viviandelcarmen.cuevascaballero@viep.com.mx } \\
\text { orcid.org/0000-0002-9576-6839 } \\
\text { linkedin.com/in/viviancuevaseduinternacional } \\
\text { scholar.google.com.mx/citations?hl=en\&user=hv6ruLAAAA }
\end{array}
$$

Es Maestra en Liderazgo Organizacional, Política y Desarrollo, con especialidad en Educación Internacional, por parte de la Universidad de Minnesota y posee una Especialidad en Marketing Internacional del Instituto de Estudios Bursátiles, centro adscrito a la Universidad Complutense de Madrid. De manera adicional, forma parte del comité de expertos evaluadores para el Consejo Quintanarroense de Ciencia y Tecnología (CoQcrt), así como de la Asociación Mexicana para la Educación Internacional (AMPEI) y de la Sociedad Mexicana de Educación Comparada (sOMEc). Actualmente es becaria conacrt para cursar sus estudios en el Doctorado en Sistemas y Ambientes Educativos en la Benemérita Universidad Autónoma de Puebla (BUAP) y es docente universitaria. 
"De pandemias, movilidad al extranjero y resiliencia: perspectivas estudiantiles y docentes" Josefina Guerrero García, Ricardo Villegas Tovar y Vivian Cuevas Caballero Vol. 22, Núm. 5, septiembre-octubre 2021

Revista Digital Universitaria

\section{Vivimos en tiempos de conectividad y globalización}

El mundo en el que vivimos hoy en día es cambiante e interconectado, no únicamente en el sentido digital, sino económico y social. La expansión de algunas empresas a nivel mundial y las políticas públicas creadas por los gobiernos para promover una mayor cooperación económica han propiciado el incremento en los flujos de movilidad de personas, generando así sociedades más plurales, diversas y multiculturales.

El ser capaz de comunicarse y trabajar eficazmente en entornos donde los individuos tienen diversos antecedentes interculturales ha sido identificado como una capacidad deseable por varias organizaciones con misiones globales (Bikson et al., 2003). Por ejemplo, en el ámbito empresarial e incluso gubernamental, la existencia de profesionistas con visión global que sean competentes interculturalmente, es algo no solamente valorado, sino considerado como necesario. Se entiende de manera general a la competencia intercultural como la habilidad de un individuo para conocerse a sí mismo y para comunicarse y desarrollarse en ambientes multiculturales de manera eficiente (Chen y Starosta, 1997; Deardorff, 2006).

Por ejemplo, conforme al estudio Culture at Work (2013) realizado por el British Council en colaboración con el Booz Allen Hamilton y el organismo Ipsos Public Affairs, a un grupo de poco más de 360 empleadores de diversas organizaciones en nueve países, se destacó que las mismas reconocen un valor comercial claro en la contratación de personal que pueda trabajar eficazmente con personas y organizaciones de orígenes culturales diferentes a los propios, haciendo alusión a que los individuos que poseen esas habilidades para colaborar con personas de otras nacionalidades pueden apoyar en la atracción de nuevos clientes, trabajar más eficientemente en equipos diversos y respaldar positivamente la marca y la reputación de su organización (British Council, Ipsos Public Affairs y Booz Allen Hamilton, 2013).

Imagen 1. Procesos de comunicación y globalización. Fuente: rawpixel.
Es, entonces, dentro del

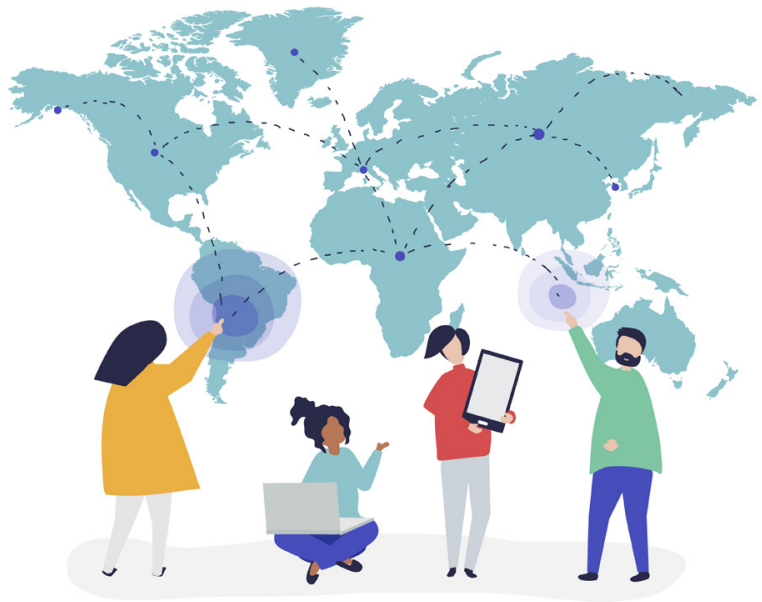
marco de esta transformación social e integración económica, que las universidades se ven impulsadas para incrementar el número de acciones que promuevansuinternacionalización y diversidad intercultural, con el fin de formar profesionistas preparados para este mundo cada vez más competitivo. Y cuando se habla de actividades de internacionalización, los programas de movilidad estudiantil y docente suelen ser 
"De pandemias, movilidad al extranjero y resiliencia: perspectivas estudiantiles y docentes" Josefina Guerrero García, Ricardo Villegas Tovar y Vivian Cuevas Caballero Vol. 22, Núm. 5, septiembre-octubre 2021

Revista Digital Universitaria

dos de las principales acciones promovidas por las instituciones. La movilidad estudiantil implica que los estudiantes realicen estancias en otra institución que no sea la de origen, con el fin de cursar asignaturas, realizar prácticas, participar en investigaciones o tomar cursos cortos. En el caso de la movilidad docente, de igual manera, comprende una estancia en otra institución con el fin de realizar investigación, impartir asignaturas o presentar ponencias, entre otros.

\section{La movilidad estudiantil y docente en tiempos de pandemia ¿es posible? Hallazgos y percepciones}

Con la llegada y expansión del SARS-CoV-2, virus causante de la covid-19, se generó una afectación masiva a diversos sectores en el mundo, incluyendo, por supuesto, a la educación. Refiriéndonos en particular al tema que nos atañe, la mayor parte de los programas gubernamentales de becas e incentivos a la movilidad, tales como la convocatoria de becas de movilidad a Canadá denominada ELAP (Emerging Leaders of the Americas Program) o la convocatoria de Becas Alianza del Pacífico, entre otras, fueron postergados o cancelados. Incluso algunos expertos han expresado que los flujos de movilidad estudiantil internacional tardarán hasta 5 años para volver a sus niveles alcanzados en la era precovid (Gácel-Ávila, 2020; Marginson, 2020); o que, debido a las restricciones presupuestarias, las becas e incentivos se verán considerablemente reducidos, lo que provocará que los números de movilidad — de por sí incipientes - se reduzcan aún más, haciendo la participación en este tipo de programas casi exclusiva para aquellos que puedan costearla.

Ante este panorama, pueden surgir las preguntas: ¿es, entonces, el fin de los programas de movilidad estudiantil y docente?, y ¿ha cambiado esto la percepción e interés de los estudiantes y docentes sobre el hecho de realizar una movilidad a otro país, a corto plazo? Respecto a estas cuestiones, con la finalidad de explorar de forma directa las percepciones de algunos individuos sobre los programas de movilidad bajo la nueva normalidad, se realizaron 2 acciones exploratorias.

La primera fue efectuar la aplicación de una breve encuesta durante los meses de abril a julio del año 2020, a una muestra aleatoria de 52 estudiantes y docentes que con anterioridad fueron participantes de movilidad, con el fin de conocer sus percepciones sobre seguridad sanitaria, y adecuaciones migratorias y de estudios bajo la nueva normalidad. En este sentido, la intención fue la de recibir la opinión de personas que ya habían vivido una experiencia de movilidad en años previos, con todas las implicaciones positivas y negativas que conlleva

${ }^{1}$ La encuesta puede consultarse en este enlace. Por el contrario, si lo que se desea es conocer los resultados generales, puede contactar a la investigadora, al correo: viviandelcarmen. cuevascaballero@viep.com.mx. y si, a pesar de la situación actual, estarían dispuestos a participar en un nuevo programa de movilidad si la oportunidad surgiera. De los encuestados, 35\% fueron hombres y $65 \%$ mujeres (ver figura 1), mientras que por rango de edad alrededor de 25\% oscilaron entre los 20 y 31 años; 15\%, entre 31 y 42; 10\% entre 42 y 53, y 5\%, entre 53 y 64 (ver figura 2). 
Figura 1. Distribución de encuestados por sexo. Fuente: elaboración propia.

Figura 2. Distribución de encuestados por rango de edad. Fuente: elaboración propia.

Figura 3. Interés en la movilidad. Fuente: elaboración propia.

\section{Distribución de encuestados/as POR SEXO}

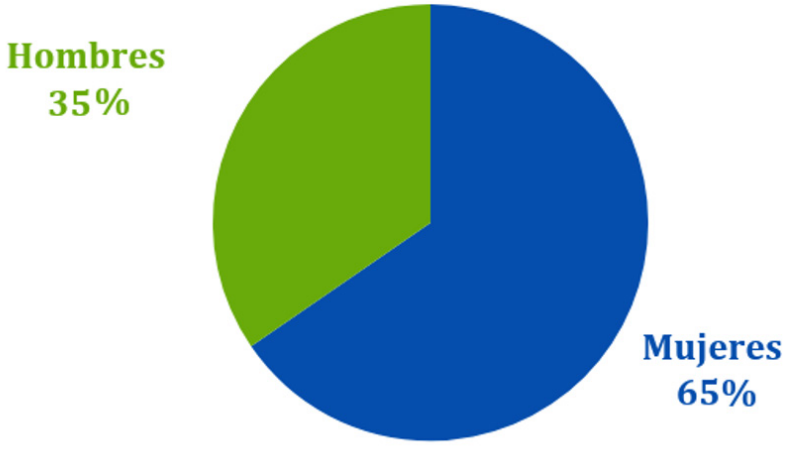

DISTRIBUCIÓN POR RANGOS DE EDAD

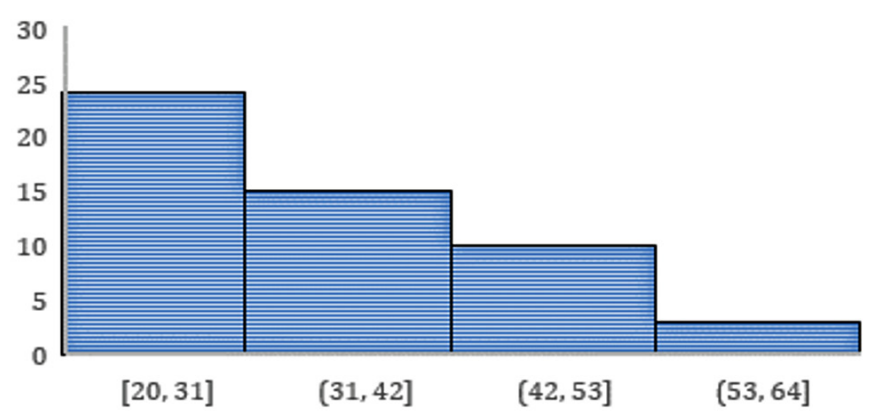

A pesar de que durante el período de aplicación de la encuesta existía un bombardeo de información sobre la pandemia, la percepción generalizada fue positiva (ver figura 3). Por ejemplo, cerca de 78\% de los encuestados indicó ante la pregunta: "Con la actual situación de la pandemia mundial inminente, ¿te atreverías a vivir (ovolver a vivir) una experiencia internacional?", que aún se sentían motivados a participar de nueva cuenta en un esquema de movilidad física.

Interés de vivir una experiencia de movilidad a pesar de la pandemia

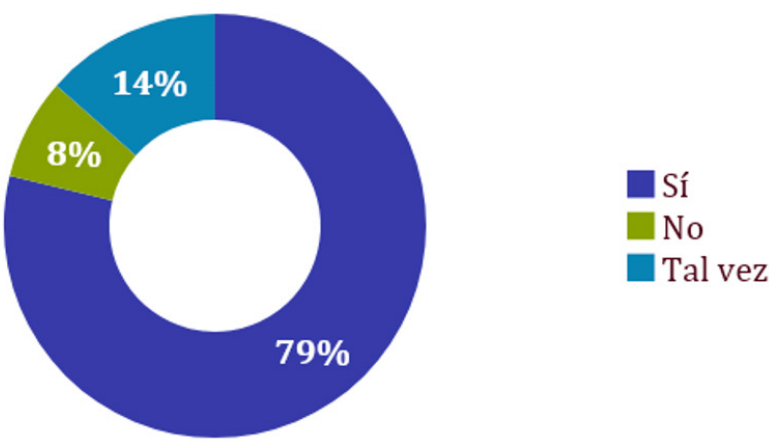


"De pandemias, movilidad al extranjero y resiliencia: perspectivas estudiantiles y docentes" Josefina Guerrero García, Ricardo Villegas Tovar y Vivian Cuevas Caballero Vol. 22, Núm. 5, septiembre-octubre 2021

Revista Digital Universitaria

De igual forma, si existiera la oportunidad de participar en una movilidad a corto plazo (en un período de un año), 67\% de los encuestados respondió que sí vivirían dicha experiencia. Y es que, dentro de esta motivación intrínseca, reposa el hecho de que, una vez que se vive una experiencia en el extranjero, los temores ante circunstancias complicadas que se puedan vivir en otro país en cierta medida se aminoran.

La segunda acción fue la de implementar tresseminarios virtuales enfocados a ofrecer información sobre la importancia de vivir una experiencia internacional, así como de algunos programas y oportunidades a corto y mediano plazo. Estos seminarios se llevaron a cabo durante el período de verano del año 2020, poco antes de que iniciara el ciclo escolar 2020-2021. La distribución de participación de una asistencia aproximada fue de 187 estudiantes, provenientes de cinco diferentes carreras en tres universidades públicas ubicadas en tres diferentes estados del país (ver tabla 1).

\begin{tabular}{|llc|}
\multicolumn{1}{c}{ Universidad } & Localización & $\begin{array}{c}\text { Asistencia } \\
\text { aproximada }\end{array}$ \\
\hline Institución 1 & Quintana Roo & 67 \\
Institución 2 & Veracruz & 42 \\
Institución 3 & Querétaro & 78 \\
\hline
\end{tabular}

Los seminarios virtuales tuvieron una duración aproximada de 50 minutos y fueron impartidos a través de horarios de tutoría grupal, con el apoyo y conducción de un profesor y/o responsable de movilidad estudiantil en dichas instituciones y en los mismos se tocaron tres diferentes temáticas:

2 Es importante recalcar que durante el año 2020 diversas convocatorias y programas de apoyo a la movilidad docente y estudiantil (por ejemplo la Alianza del Pacífico, Emerging Leaders of the Americas Program, entre otras) provistas por organismos y gobiernos fueron suspendidas o postergadas. Sin embargo, para el caso de México, otras convocatorias como el caso de los programas MEXFITEC, MEXPROTEC Y becas a extranjero del CONACYT continuaron vigentes, y si bien los flujos de movilidad en las mismas se vieron considerablemente reducidos, y aquellos que iniciaron sus estudios tuvieron que tomar ciertas medidas de confinamiento mandatorio por 14 días al momento de llegar a los países destino, lo cierto es que continuó la movilidad de estudiantes a nivel de licenciatura o posgrado.

1. Destacar la importancia de ser competentes interculturalmente, haciendo uso de ejemplos de la vida cotidiana y situaciones hipotéticas en el caso de que los estudiantes estuviesen realizando una movilidad en el extranjero, o conviviendo con determinada frecuencia con personas de una nacionalidad diferente a la mexicana, en su ámbito educativo, laboral o familiar.

2. Otorgar recomendaciones a todos los estudiantes para redactar cartas de postulación a programas de becas, de una forma adecuada, con el fin de incrementar sus posibilidades de obtener apoyos económicos.

3. Brindar información sobre algunas convocatorias de movilidad existentes para los años 2020 a 2022², la documentación requerida, así como el proceso y los trámites necesarios para poder tener un expediente adecuado.

Como resultado de esta segunda acción se destaca el hecho de que los estudiantes, tras participar en los seminarios, se mostraron no solamente interesados en conocer las opciones de movilidad a las que podían aplicar, sino que al menos 10\% de ellos externaron el estar aprovechando la modalidad de estudios en línea, para fortalecer alguna habilidad o conocimiento extracurricular, como el aprendizaje de un segundo idioma, con la finalidad de que, cuando 
"De pandemias, movilidad al extranjero y resiliencia: perspectivas estudiantiles y docentes" Josefina Guerrero García, Ricardo Villegas Tovar y Vivian Cuevas Caballero Vol. 22, Núm. 5, septiembre-octubre 2021

Revista Digital Universitaria

las convocatorias y programas de movilidad física se reactiven, pudieran ser candidatos más adecuados.

\section{Un panorama ligeramente alentador}

Imagen 2. Estudiante esperanzada. Fuente: benzoix.

${ }^{3}$ Programas tales como Becas de Posgrado a Estados Unidos, Fulbright de comexus y Becas de Posgrado a Francia, a través de Campus France, entre otras.

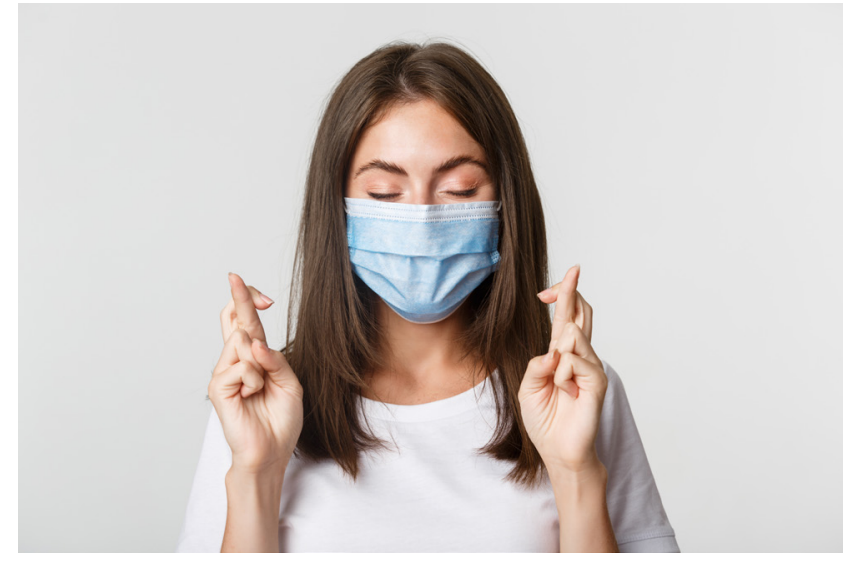

Hallazgos como los planteados traen a la mesa diversas preguntas: ¿sería posible que esta percepción positiva, que muestran tanto los antiguos participantes de movilidad como los estudiantes que tomaron los seminarios, esté basada en la esperanza de que las pandemias (independientemente del virus que se trate) puedan verse frenadas a corto plazo a través de los avances médicos? ¿Será que el vivir una experiencia previa vuelve a los individuos más resilientes ante las situaciones adversas? O incluso, ¿puede deberse a qué, como mencionó 10\% de los encuestados, "hay que vivir y aprovechar las oportunidades exista o no pandemia"?

Estas preguntas pudieran, por el momento, no quedar resueltas del todo y ciertamente representan una ventana de oportunidad para futuras investigaciones. Lo que sí puede afirmarse es el hecho de que, para el actual año 2021, algunos programas y convocatorias de movilidad están iniciando su reactivación para el ciclo escolar 2021-2022³ y los avances médicos están permitiendo que la población en diversos países inicie procesos de inmunización, los cuales permitirán ir abriendo espacio a la movilidad estudiantil y docente.

No cabe duda de que la llegada de la pandemia ha generado enormes transformaciones sociales y miles de pérdidas humanas y económicas. Ciertamente, el riesgo de contagio continúa como algo latente, lo que ha generado que las fronteras en diversos países continúen cerradas o con acceso restringido. Esto, por supuesto, podría hacernos pensar en el hecho de vivir una experiencia internacional sea imposible, pero para algunos individuos, la intención de realizar una movilidad continúa. En efecto, es muy importante recalcar que si bien las dos actividades realizadas a través de esta exploración a una muestra de poco más de 200 individuos no representan la totalidad de las percepciones de los estudiantes y docentes en el país, sí sirve como referencia para el lector sobre la opinión de ciertos estudiantes y docentes. 
"De pandemias, movilidad al extranjero y resiliencia: perspectivas estudiantiles y docentes" Josefina Guerrero García, Ricardo Villegas Tovar y Vivian Cuevas Caballero Vol. 22, Núm. 5, septiembre-octubre 2021

Revista Digital Universitaria

La nueva normalidad ha provocado que las modalidades educativas estén cambiando, asimismo, las funciones sustantivas de las universidades deben continuar; por lo que establecer acciones que promuevan el fortalecimiento de las competencias profesionales y personales, el perfeccionamiento de otros idiomas, la adquisición de nuevos conocimientos y la generación de avances científicos o académicos en las nuevas generaciones es tarea necesaria para formar ciudadanos más preparados y competitivos, empáticos, comprensivos y quizá más humanitarios; cualidades que, hoy en día, son cruciales, en especial considerando los nuevos tiempos que se viven.

\section{Referencias}

Bikson, T. K., Treverton, G. F., Moini, J. S. y Lindstrom, G. (2003). New Challenges for International Leadership: Lessons from Organizations with Global Missions. RAND Corporation. https://www.rand.org/pubs/monograph_reports/MR1670.html

* British Council, Ipsos Public Affairs y Booz Allen Hamilton. (2013). Culture AT WORK. The value of intercultural skills in the workplace. https://www.britishcouncil.org/sites/ default/files/culture-at-work-report-v2.pdf

* Chen, G.-M., Starosta, W. J. (1997). A Review of the Concept of Intercultural Sensitivity. Human Communication, 1, 1-16. https://digitalcommons.uri.edu/com_ facpubs/38/

- Deardorff, D. K. (2006). Identification and Assessment of Intercultural Competence as a Student Outcome of Internationalization. Journal of Studies in International Education, 10(3), 241-266. https://doi.org/10.1177/1028315306287002

* Gácel-Ávila, J. (2020). covid-19: Riesgosy oportunidades para la internacionalización de la educación superior en México. ESAL - Revista de Educación Superior en América Latina, 37-40. https://cutt.ly/BWA8H7T

* Marginson S. (2020, March 26). Global He as we know it has forever changed. Times Higher Education (THE). World University Rankings. https://cutt.ly/fWSzSCm

\section{Cómo CITAR ESTE ARTículo}

* Guerrero García, Josefina, Villegas Tovar, Ricardo y Cuevas Caballero, Vivian. (2021, septiembre-octubre). De pandemias, movilidad al extranjero y resiliencia: Perspectivas estudiantiles y docentes. Revista Digital Universitaria (RDU), 22(5). http://doi.org/10.22201/cuaieed.16076079e.2021.22.5.12 